\title{
Gestão participativa na Estratégia Saúde da Família: reorientação da demanda à luz do Método Paideia
}

\author{
Participatory management in the Family Health Strategy: \\ reorientation of demand in the light of the Paideia Method
}

Mykaelly Pereira Clemente', Antonio Germane Alves Pinto', Alissan Karine Lima Martins ${ }^{\mathbf{1}}$

DOI: $10.1590 / 0103-1104202112905$

RESUMO Objetivou-se descrever a construção de um plano de ação de corresponsabilização entre gestores, profissionais e usuários, para a reorientação da demanda espontânea em uma Unidade de Saúde da Família, por meio de ferramentas de gestão participativa. Tratou-se de um estudo intervencionista do tipo pesquisa-ação, realizado com uma equipe de Estratégia Saúde da Família do município de Petrolina (PE). Participaram do estudo 11 sujeitos, selecionados pela técnica de amostragem da representatividade qualitativa, sendo 3 gestores da atenção básica do município, 4 profissionais de saúde da Estratégia Saúde da Família envolvida no estudo e 4 líderes comunitários, representantes dos usuários. O referencial teórico adotado para a análise da intervenção foi o método de análise e cogestão de coletivos, o Método Paideia. O estudo evidenciou o despreparo dos coletivos para atuarem na gestão participativa, ao tempo que revelou que as possibilidades de reestruturação dos serviços são otimizadas quando pensadas de maneira democrática e corresponsável. Considerou-se que as principais contribuições deste estudo foram a sensibilização e a mobilização dos sujeitos para atuarem de maneira participante no planejamento e na gestão dos problemas de saúde.

PALAVRAS-CHAVE Estratégia Saúde da Família. Gestão em saúde. Necessidades e demandas de serviços de saúde. Participação da comunidade.

ABSTRACT The objective was to describe the construction of a co-responsibility action plan involving managers, professionals and users, aimed at reorienting spontaneous demand in a Family Health Unity, by means of participatory management tools. This was an interventional research study, the action-research type, carried out with a Family Health Strategy team in the municipality of Petrolina (PE). The study involved eleven participants, who were selected using the qualitative representativeness sampling technique, and included three primary care managers in the municipality, four health professionals from the Family Health Strategy involved in the study and four community leaders, representatives of users. The theoretical framework adopted for the analysis of the intervention was the method of analysis and co-management of collectives - the Paideia method. The study revealed the unpreparedness of collectives to act in participatory management, while showing that possibilities of restructuring services are optimized when thought of in a democratic and co-responsible way. It was considered that the main contributions of this research were the awareness and the mobilization of the subjects to act in a participatory way in the planning and management of health problems.

1 Universidade Regional do Cariri (Urca) - Crato (CE), Brasil.

mykaellypc@hotmail.com
KEYWORDS Family Health Strategy. Health management. Health service needs and demands. Community participation. 


\section{Introdução}

A Estratégia Saúde da Família (ESF) é considerada como um meio de expansão, qualificação e consolidação da atenção primária por favorecer uma reorientação do processo de trabalho, com maior potencial de aprofundar os princípios e diretrizes do Sistema Único de Saúde (SUS) ${ }^{\mathbf{1} 2}$.

Franco e Merhy ${ }^{2}$ citam a ESF como uma tentativa de reorganização dos serviços de saúde, tendo como pressupostos a produção do cuidado, um processo de trabalho usuário-centrado e relações acolhedoras, capazes de gerarem vínculos, em um processo produtivo que aposta nas tecnologias mais relacionais para a assistência aos usuários.

Nessa perspectiva, o planejamento participativo se configura na adoção de práticas e mecanismos inovadores, que efetivam a participação popular e abrangem um sistema de cooperação, compartilhamento, transparência e protagonismo social como formas de promover o exercício democrático ${ }^{3}$.

A gestão participativa, no âmbito dos serviços, implica a ampliação de arranjos organizacionais montados para estimular a produção/ construção de sujeitos e de coletivos no gerenciamento de ações e práticas políticas do controle social ${ }^{4,5}$.

Ainda que de forma incipiente, espaços de participação social vêm sendo criados na atenção básica, com o objetivo de reconhecer sujeitos capazes de estabelecerem uma interlocução dialógica com os serviços de saúde e possibilitar um incremento de estratégias de luta e de enfrentamento aos problemas locais. Portanto, ampliar tais espaços e reivindicar a participação social dos usuários e dos trabalhadores em associação com os gestores, no processo de planejamento social, tem sido um desafio para o planejamento participativo na $\mathrm{ESF}^{4}$.

Cotidianamente, o dimensionamento entre as demandas espontâneas e programadas também tem sido um problema enfrentado pelas equipes de ESF. Isto porque uma das grandes dificuldades do seu processo de trabalho é a necessidade de organizar o atendimento aos grupos prioritários de maior risco e vulnerabilidade, por meio de consultas programadas, sem negligenciar a busca espontânea pelo serviço de saúde e o atendimento às urgências ${ }^{6,7}$.

Pesquisas relatam que muitos fatores contribuem para o aumento da demanda espontânea. Entre eles, destacam-se os de origem estrutural, como unidades de saúde distantes dos demais serviços da Rede de Apoio à Saúde (RAS) e equipes de Saúde da Família que atendem a um contingente populacional acima do preconizado pelo Ministério da Saúde (MS). Também há aqueles de natureza cultural, historicamente alicerçados em práticas e paradigmas de saúde6-9.

Rocha ${ }^{7}$ enfatiza que a demanda espontânea exacerbada tem interferido diretamente no funcionamento da ESF, fazendo com que as equipes deixem de empregar ações preventivas para realizarem intervenções curativas e de caráter imediato. Esta inversão de práticas implica o aumento das patologias preveníveis e a agudização das crônicas, o que reforça o binômio saúde-doença e enfraquece as práticas assistenciais baseadas na prevenção e promoção de saúde.

Para evitar um retrocesso assistencial, o MS tem lançado manuais instrutivos direcionados ao acolhimento à demanda espontânea, a fim de orientar as equipes em seus processos de trabalho ${ }^{10,11}$.

Araújo e Assis ${ }^{12}$ dizem que, apesar de o MS dispor de protocolos, construídos por consensos científicos que direcionam a atuação dos trabalhadores da ESF, é preciso que eles sejam utilizados com análise crítica e adaptados à realidade da população, frente aos principais agravos que acometem a comunidade.

Ademais, os autores ressaltam que é necessário promover encontros individuais e coletivos, que estimulem a criatividade da equipe, para que, no confronto com as necessidades sociais e de saúde da comunidade, ela seja capaz de mediar respostas adequadas e focadas nas pessoas ${ }^{12}$. 
Foi mediante essa proposta e o uso do diálogo como práxis social que este estudo teve por objetivo descrever a construção e pactuar um plano de ação de corresponsabilização entre gestores, profissionais e usuários, para a reorientação da demanda espontânea em uma Unidade de Saúde da Família (USF), por meio de ferramentas da gestão participativa, entre limites e possibilidades.

\section{Material e métodos}

Tratou-se de um estudo intervencionista do tipo pesquisa-ação com abordagem qualitativa, realizado em uma Unidade Básica de Saúde (UBS) do Projeto Maria Tereza localizada no município de Petrolina (PE), nos anos de 2018 e 2019.

As pesquisas intituladas como intervencionistas sedimentam-se na intenção de valorizar uma produção de conhecimento que favoreça o surgimento de novos atores no processo de pesquisa e que, por sua vez, sejam corresponsáveis pela condução e construção do conhecimento coletivo ${ }^{13}$.

Thiollent ${ }^{14}$ diz que a pesquisa-ação busca elucidar problemas sociais cientificamente relevantes por intermédio de grupos em que se reúnem pesquisadores, membros da situação-problema e outros atores e parceiros interessados no assunto.

Uma característica peculiar da pesquisa-açãoé a existência prévia de um processo investigativo, uma vez que o problema e suas variáveis são desconhecidos ou necessitam de conhecimento adicional e de uma maior aproximação do pesquisador com a realidade investigada ${ }^{15}$.

Participaram do estudo 11 sujeitos selecionados pela técnica de amostragem da representatividade qualitativa, sendo 3 gestores responsáveis pela atenção básica do município, 4 profissionais de saúde da ESF envolvida no estudo - médico, técnico de enfermagem, Agente Comunitário de Saúde (ACS) e recepcionista - e 4 líderes comunitários, representantes dos usuários. Salienta-se que a enfermeira foi excluída da amostra por ser a pesquisadora direta, e a equipe de odontologia também não constou na amostragem por ter sido substituída ao longo da intervenção.

A técnica de amostragem da representatividade qualitativa trata de um pequeno número de pessoas intencionalmente escolhidas em função da relevância que apresentam em um determinado assunto, isto é, em função de sua representatividade social dentro da situação considerada ${ }^{\mathbf{1 4}}$.

A pesquisa foi estruturada em dois momentos: o primeiro, exploratório, e o segundo, de intervenção, buscando contemplar as 12 etapas enumeradas por Thiollent, geradoras e norteadoras de uma pesquisa-ação.

A etapa exploratória abrangeu a seleção dos sujeitos da pesquisa em função da representatividade social que eles apresentavam diante da problemática estudada. O diagnóstico do perfil dos usuários que buscam atendimento de maneira espontânea no serviço de saúde foi elaborado através de dados coletados em fontes secundárias, relatórios da Estratégia de Informatização da Atenção Primária à Saúde (e-SUS APS) e livro de registro da demanda da unidade; e em fontes primárias, a partir de entrevistas semiestruturadas.

A fase de intervenção contemplou a apresentação dos dados da etapa exploratória, a elaboração do tema da pesquisa, a colocação dos problemas, a formulação de hipóteses, o levantamento das necessidades de aprendizagem do grupo de intervenção e a mediação de saberes formais e informais. Foi conduzida pelo seminário de intervenção, que culminou com a elaboração do plano de ação, estruturado a partir das diretrizes do Planejamento Estratégico Situacional (PES).

O referencial teórico-metodológico adotado para a análise da intervenção foi o método de análise e cogestão de coletivos de Gastão Wagner Campos, conhecido como Método Paideia (ou Método da Roda) ${ }^{4}$. Tal referência parte do pressuposto de que a gestão deve ser uma tarefa coletiva e não monopolizada por pessoas que acumulam um maior capital econômico e cultural. Desponta como possibilidade de reprodução e ampliação de espaços de democratização, com potencial para 
influir sobre a produção da subjetividade dos atores, em uma atmosfera de reflexão, críticas, conflitos, produção e transformação. Adequa-se, neste sentido, à avaliação e ao gerenciamento das ações e comportamentos das pessoas ao trabalharem em equipe, e tem suas bases de análises referenciadas por núcleos temáticos relativos ao mundo e ao sujeito.

Mediante observação participante, realizada tanto na fase exploratória quanto na de intervenção, nas quais as impressões da pesquisadora foram fielmente registradas em um diário de campo, este estudo analisou o comportamento dos sujeitos e as propostas intervencionistas a fim de encontrar pontos de convergência e divergência entre tais sujeitos, além de pontos de análises propostos pelos núcleos temáticos do método.

No primeiro momento, os resultados finais foram divulgados apenas de maneira interna no grupo de pesquisa. Posteriormente, nos meios sociais e acadêmicos, por meio de relatórios às instâncias envolvidas e através da publicação dos produtos desta pesquisa, seguindo as orientações metodológicas da pesquisa-ação.

Enfatiza-se que o estudo obedeceu aos preceitos éticos da pesquisa envolvendo seres humanos, conforme parecer do Comitê de Ética em Pesquisa da Universidade à qual estão afiliados os pesquisadores, sob $\mathrm{n}^{\circ}$ 3.203.082.

\section{Resultados}

\section{Descrevendo o seminário de intervenção e a construção do plano para a reorientação da demanda espontânea}

O seminário de intervenção reuniu os profissionais de saúde, os gestores e as lideranças locais para debaterem a problemática da demanda espontânea na UBS e pactuarem, de maneira consensual e democrática, as estratégias de melhorias assistenciais.
Participaram do encontro os sujeitos da pesquisa e colaboradores vinculados à Universidade de Pernambuco (UPE).

Inicialmente, houve uma acolhida aos participantes na abertura do seminário, que ocorreu com uma dinâmica de sociabilização, objetivando apresentar ao grupo o nome de cada participante e sua representação social, assim como sensibilizá-los quanto à importância daquele encontro.

Seguiu-se a esse primeiro momento uma apresentação geral da localidade e da unidade de saúde: estrutura física, população adscrita, indicadores de saúde e dificuldades de acesso aos demais serviços de referência em saúde do município. Foram apresentados, também, os dados da fase exploratória da pesquisa, destacando o itinerário do usuário na UBS, o quantitativo de consultas realizadas por demanda espontânea e por demanda programada, com destaque para o quantitativo de pessoas que procuram o serviço e saem sem atendimento médico ou de enfermagem. Apresentaram-se, ainda, o perfil da demanda espontânea e as principais queixas referidas para o atendimento.

Naquele momento, houve uma inquietação no grupo e alguns tentaram responsabilizar a gestão municipal pela situação, o que fez necessária a intervenção da pesquisadora para mediar o conflito. Para isso, foi utilizado um vídeo de sensibilização, que ressaltava a necessidade de uma corresponsabilização entre sujeitos para solucionar problemas complexos ${ }^{16}$.

Uma vez sanados os conflitos de interesses, foi colocado o tema da pesquisa: Como melhorar o processo de trabalho na ESF do Projeto Maria Tereza e conciliar o atendimento à demanda agendada e o acolhimento à demanda espontânea?

Após o processo de debate, mediado pela apresentação dos dados da fase exploratória, colocaram-se os problemas: a questão da demanda nos serviços de saúde é cultural e está associada ao desconhecimento da proposta de trabalho da ESF; tem relação com a deficiência de recursos humanos, a infraestrutura 
da unidade e a fragilidade no acolhimento à demanda espontânea.

A construção do plano de ação foi norteada pela seguinte hipótese: que ações podem ser pactuadas, a partir de uma aproximação de coletivos, para organizar a demanda nos serviços de saúde e intervir nos problemas listados?

Devido à heterogeneidade do grupo e à identificação prévia de necessidades de aprendizagem, foi realizada uma mediação de saberes formais e informais, por técnicos colaboradores vinculados à UPE, que trouxeram para a discussão elementos teóricos acerca da ESF, seu processo de trabalho, políticas de saúde e aspectos da gestão participativa em saúde.

Dado esse trajeto, o plano de ação propriamente dito foi produzido de maneira democrática e com a elaboração de metas coletivas pactuadas pelos sujeitos, por meio do uso da ferramenta do PES.

Segue, pois, o produto final dessa intervenção, nos quadros seguintes:

Quadro 1. Planejamento Estratégico Situacional para o primeiro problema da matriz de intervenção

\begin{tabular}{|c|c|}
\hline \multicolumn{2}{|c|}{ O PROBLEMA DA DEMANDA ESTAVA ASSOCIADO AO DESCONHECIMENTO DA PROPOSTA DE TRABALHO DA } \\
\hline META/OBJETIVOS: & $\begin{array}{l}\text {-Específico: Realizar sensibilização comunitária sobre o propósito do trabalho da } \\
\text { ESF; } \\
\text {-Mensurável: Entregar panfletos educativos em todos os domicílios da localidade } \\
\text { cobertos por ACS; } \\
\text {-Alcançável: Os ACS já visitavam mensalmente os domicílios, podendo contribuir } \\
\text { para essa sensibilização em massa; } \\
\text {-Relevante: População esclarecida poderia otimizar o uso dos serviços da UBS e } \\
\text { contribuir para a reorientação da demanda; } \\
\text {-Prazo: Início em até } 90 \text { dias e permanência contínua. }\end{array}$ \\
\hline ESTRATÉGIA: & $\begin{array}{l}\text { Promover processos educativos e de orientação comunitária nas áreas e em sala } \\
\text { de espera. }\end{array}$ \\
\hline PLANO DE AÇÃO: & $\begin{array}{l}\text { Os profissionais elaborariam um folder ou panfleto educativo destinado a orientar } \\
\text { a comunidade sobre o propósito do trabalho da ESF e o funcionamento da UBS. A } \\
\text { gestão se responsabilizaria pelas cópias, que seriam entregues nos domicílios du- } \\
\text { rante as visitas dos ACS e seriam utilizadas em atividades educativas realizadas } \\
\text { em sala de espera pelos demais funcionários da ESF. E, também, em atividades } \\
\text { locais promovidas pelas lideranças comunitárias. }\end{array}$ \\
\hline AVALIAÇÃO DOS RESULTADOS: & $\begin{array}{l}\text { A avaliação da estratégia seria viabilizada pela análise do motivo da procura } \\
\text { pelo atendimento, a ser realizado trimestralmente, nos registros de atendimento } \\
\text { da demanda espontânea, e pelos relatórios gerados pelo sistema de prontuário } \\
\text { eletrônico. }\end{array}$ \\
\hline
\end{tabular}

POTENCIALIDADES E FRAGILIDADES DA ESTRATÉGIA: A mão de obra necessária para essa ação já estaria disponível, sem que fosse necessário aguardar a criação das novas equipes de ESF. Mudanças de comportamento e de cultura são processos com efeito em longo prazo.

Fonte: Elaboração própria. 
Quadro 2. Planejamento Estratégico Situacional para o segundo problema da matriz de intervenção

\title{
A PROBLEMÁTICA DA DEMANDA ESTAVA ASSOCIADA AO NÚMERO INSUFICIENTE DE EQUIPES PARA ATENDER À POPULAC̣̃̃O E AGRAVADA PELA ESTRUTURA FÍSICA INADEQUADA DA UBS
}

\begin{abstract}
META/OBJETIVOS:
-Específico: Ampliar o número de equipes de ESF e melhorar a estrutura física da unidade;

- Mensurável: Adquirir mais duas equipes de ESF e criar uma nova UBS em uma das áreas da localidade;

- Alcançável: Fazer a adesão da UBS ao Programa Saúde na Hora para, de imediato, conseguir uma equipe provisória, que, posteriormente, fosse transformada em equipe de ESF;

-Relevante: A chegada de mais uma equipe, a princípio, desafogaria parte do serviço. Posteriormente, com a existência de duas equipes de ESF, seria possível fazer o redimensionamento da população e otimizar os atendimentos.

ESTRATÉGIA:

PLANO DE AÇÃO:

AVALIACÃO DOS RESULTADOS:

Inicialmente, reformar a estrutura física existente; redimensionar a população adscrita, de acordo com os preceitos da Política Nacional da Atenção Básica, a partir da implantação de mais duas equipes de ESF em sedes mais próximas às áreas; e adesão provisória ao Programa Saúde na Hora. Tudo isto, a fim de amenizar a problemática enquanto se daria o processo de ampliação do número de equipes e da estrutura física.

Com a utilização de recurso próprio municipal, seria realizada uma reforma para a manutenção da estrutura, contemplando serviços de pintura, elétricos e hidráulicos. A gestão, com base no quantitativo da população do Km 25, solicitaria ao Ministério da Saúde a aquisição de mais duas equipes de ESF para a localidade. Por meio de emenda parlamentar, seria levantado o capital para a construção de outra sede, mais acessível às áreas, e para a ampliação da sede da vila. Tratando-se este de um processo demorado e burocrático, as gestoras fariam um cadastro provisório da equipe no Programa Saúde na Hora, o que permitiria a contratação de uma nova equipe para estender o horário de funcionamento da unidade e já proporcionaria um novo redimensionamento populacional, desafogando as equipes existentes no momento.

O instrumento de avaliação externa do Programa de Melhoria do Acesso e da Qualidade (PMAQ), no quesito observação na unidade básica de saúde, seria utilizado para avaliar melhorias oriundas dessa estratégia.
\end{abstract}

POTENCIALIDADES E FRAGILIDADES DA ESTRATÉGIA: O interesse manifestado pela gestão, de agilizar e priorizar essa ação, foi uma potencialidade da estratégia; e a fragilidade se voltou para a dependência política dessa ação, com possibilidade de atraso para cumprir os prazos em decorrência do atrelamento a emendas parlamentares e prazos ministeriais.

Fonte: Elaboração própria. 
Quadro 3. Planejamento Estratégico Situacional para o terceiro problema da matriz de intervenção

\begin{tabular}{|c|c|}
\hline \multicolumn{2}{|c|}{ A PROBLEMÁTICA DA DEMANDA ESTAVA ASSOCIADA À FRAGILIDADE DO ACOLHIMENTO } \\
\hline META/OBJETIVOS: & $\begin{array}{l}\text {-Específico: Assegurar que as pessoas que procurassem o serviço fossem aten- } \\
\text { didas; } \\
\text {-Mensurável: Atender diariamente todos os usuários que chegassem à unidade; } \\
\text {-Alcançável: Deixar um profissional de nível superior exclusivo para realizar o } \\
\text { acolhimento com classificação de risco; } \\
\text {-Relevante: Verificar as necessidades dos usuários que procurassem o serviço; } \\
\text {-Prazo: } 60 \text { dias. }\end{array}$ \\
\hline ESTRATÉGIA: & $\begin{array}{l}\text { Médicos e enfermeiros assumiriam o acolhimento e a classificação de risco dos } \\
\text { usuários que buscassem o serviço por demanda espontânea, por meio de rodízio } \\
\text { entre os profissionais existentes. }\end{array}$ \\
\hline PLANO DE AÇÃO: & $\begin{array}{l}\text { Os profissionais de nível superior presentes na intervenção iriam, em uma } \\
\text { reunião de equipe com os demais profissionais da UBS, organizar a agenda de } \\
\text { atendimento, de modo a deixar um dia livre para cada médico e enfermeiro assu- } \\
\text { mirem o acolhimento, fazendo rodízio entre estes, quando necessário, em função } \\
\text { de férias ou folga do profissional escalado. }\end{array}$ \\
\hline AVALIAÇÃO DOS RESULTADOS: & $\begin{array}{l}\text { A cada trimestre seria realizada uma consulta de satisfação dos usuários para } \\
\text { checar a eficácia da estratégia adotada. Além da verificação, no livro de deman- } \\
\text { das e nos sistemas eletrônicos de registro de atendimentos, da existência de } \\
\text { casos de usuários que buscam o serviço e saem sem o atendimento. }\end{array}$ \\
\hline \multicolumn{2}{|c|}{$\begin{array}{l}\text { POTENCIALIDADES E FRAGILIDADES DA ESTRATÉGIA: O consultório do profissional escalado para o dia poderia ser } \\
\text { utilizado como espaço de acolhimento, classificação de risco e atendimento. Desse modo, não seria necessário esperar } \\
\text { a ampliação da UBS para a realização de tais feitos. Nos casos de adoecimento ou falta não programada do profissional } \\
\text { escalado do dia, e sem outro de nível superior para sua substituição, o suporte ao acolhimento da demanda seria dado } \\
\text { pelos agentes de nível técnico. }\end{array}$} \\
\hline
\end{tabular}

Fonte: Elaboração própria.

\section{Avaliação da intervenção sob a luz do Método Paideia}

De acordo com Campos 4 , o Método Paideia permite uma análise de ações coletivas, a partir da interpretação da ação prática do sujeito no mundo e operando com núcleos temáticos referentes ao mundo e ao sujeito.

Dentre os núcleos temáticos referentes ao mundo, o método de Campos permite algumas reflexões acerca das interpretações das ações práticas do sujeito, a saber: quais as finalidades e os objetivos da ação humana? O produto é o único meio de análise de uma intervenção? Quais os meios utilizados pelo sujeito para conhecer e intervir em um dado contexto? Quais as tarefas de corresponsabilização adotadas pelo sujeito?

Os núcleos temáticos referentes aos sujeitos dizem respeito à existência destes no mundo, contemplando suas motivações/interesses em participar da intervenção; a capacidade dos sujeitos para estabelecerem pontes com os interesses de outros sujeitos; a análise da rede de poderes, da possibilidade de exercer o controle social; e as referências culturais e éticas dos sujeitos em relação à situação-problema.

Campos $^{4}$ afirma, ainda, que o Método Paideia avalia três critérios fundamentais em organizações de sujeitos, com propósitos intervencionistas:

1 - O reconhecimento de que uma das finalidades principais da política de gestão e do trabalho humano é a construção do bem-estar e da justiça social;

2 - O pressuposto de que a política, a gestão e o trabalho devem ser julgados, também, por suas capacidades de construir os maiores coeficientes possíveis de autonomia e de liberdade para as pessoas e instituições; 
3 - A capacidade de assegurar a resolução de conflitos e a elaboração de contratos entre interesses e valores divergentes, por meio do uso de instrumentos de convencimento e de negociação.

Diante do exposto, a intervenção desta pesquisa foi analisada considerando os núcleos temáticos e os critérios do Método Paideia.

Observou-se, ainda, na fase das entrevistas individuais, e se confirmou na postura, no comportamento e nas discussões dos usuários, no momento da intervenção, que, a princípio, a motivação destes para participar dessa intervenção partia de interesses pessoais de cunho político. Cada líder comunitário demonstrou interesse em que a nova equipe de ESF a ser constituída fosse sediada em suas áreas de representatividade, deixando a impressão de que a aquisição da nova equipe se tornaria um item de conquista individual com poder de barganha para pleitear prestígio social.

No entanto, essa tensão foi amenizada a partir da apresentação dos dados epidemiológicos de cada microárea do Projeto Maria Tereza e após a consideração desses números e da distância entre as microáreas e a possível sede da nova equipe de ESF, embora não se tenha chegado a uma definição exata do local que a sediará. Contudo, foi pactuado que seria no lugar de mais fácil acesso para a comunidade, e que possuísse os maiores indicadores de riscos e vulnerabilidades em saúde.

Em relação aos profissionais, percebeu-se que a motivação maior era organizar o serviço de maneira que houvesse diminuição da sobrecarga de trabalho. E quanto aos representantes da gestão, pareceu haver o interesse de fazer valer seu slogan político: construir um novo tempo, a partir da otimização, do apoio e da valorização de estratégias de gestão participativa.

Diante disso, as estratégias sugeridas pelos sujeitos para conhecimento e intervenção na situação partiram de suas referências culturais e éticas acerca do problema. Observou-se que a maioria das propostas foram elaboradas pelos gestores e profissionais, o que deve ter acontecido pelo fato de os usuários não compreenderem seus papéis no gerenciamento dos serviços de saúde, ou por se colocarem em uma postura de vitimização nas situações, sem se perceberem como corresponsáveis pelo problema.

Foi notória a capacidade dos sujeitos para estabelecerem pontes com os interesses de outros sujeitos, mesmo diante do paradoxo entre o interesse pessoal e a necessidade comunitária. Isso ficou evidente quando eles precisaram recuar em suas opiniões prévias e absorver propostas de trabalho, as quais, a priori, não lhes eram favoráveis, como, por exemplo, a implantação do acolhimento antes da chegada da nova equipe de ESF e do redimensionamento da população adscrita, além da reconsideração do local da sede da nova equipe por parte dos usuários, já citada anteriormente.

A análise da rede de poderes e da possibilidade de exercer o controle social foi observada de maneira incipiente nessa intervenção. Não foram percebidas propostas que contemplassem a construção de conselhos de saúde e ouvidoria locais. O grupo, nesse aspecto, se limitou a pactuar um novo encontro, com data posterior, para acompanhar o andamento das estratégias definidas.

\section{Discussão}

O planejamento, visto estrategicamente, é a ciência e a arte da governabilidade e se configura em um conjunto de princípios teóricos, procedimentos metodológicos e técnicas de grupo, que podem ser aplicados em organizações sociais que almejam a mudança situacional de uma problemática comum aos sujeitos ${ }^{17}$.

O PES é uma ferramenta desenvolvida pelo economista chileno Carlos Matus na década de 1970, quando foram percebidas falhas de planejamento mediante o uso de ferramentas tradicionais. Caracteriza-se como um instrumento de gestão passível de adaptações ou reformulações do plano, de acordo com as 
variáveis da situação, e que melhor se adequem à solução de problemas complexos ${ }^{18}$.

Nesse sentido, a partir da complexidade dos problemas listados como influenciadores da demanda espontânea no serviço estudado, optou-se pelo uso dessa ferramenta para propor um plano de intervenção, considerando as variáveis envolvidas, as potencialidades e fragilidades de cada estratégia.

Assim, houve o reconhecimento de que a problemática da demanda nos serviços de saúde está atrelada ao desconhecimento da proposta de trabalho da ESF, o que é culturalmente influenciado pelas práticas assistenciais do modelo biomédico, no qual usuários vinculam a prestação de serviço à oferta de procedimento e a exames clínicos, não reconhecendo a importância do trabalho preventivo e de promoção à saúde, desenvolvido pelas equipes de ESF.

Esmeraldo et al. ${ }^{19}$ dizem que a compreensão dos usuários ainda está dominada pela influência do modelo hegemônico, médico-centrado, focado na doença, no biológico e na cura, dissociado do contexto social e do entendimento de prevenção e promoção.

Diante disso, a equipe de intervenção propôs uma estratégia de sensibilização comunitária de corresponsabilização entre gestores, profissionais e representação local, em que a equipe de saúde elaboraria um material educativo para destacar a importância da ESF, dos serviços ofertados e do fluxo de atendimento. Esse material seria reproduzido com recursos da gestão municipal e distribuído em atividades educativas em salas de espera, visitas domiciliares e ações sociais, pelos ACS e por líderes das associações de moradores. Embora se saiba que as mudanças de comportamento e de cultura seja um processo de efeito em longo prazo, Bittencourt ${ }^{20}$ defende que a conscientização da população acerca dos objetivos e propostas da ESF é imprescindível para a organização do processo de trabalho.

À vista disso, o grupo de intervenção entendeu que não era possível redimensionar a demanda apenas com estratégias de processo de trabalho, e que seria necessária, ao considerar a população adscrita naquela localidade, a criação de mais duas equipes de ESF para desafogar o serviço. A gestão municipal se responsabilizou por viabilizar essa aquisição junto ao MS e, através de uma emenda parlamentar, por levantar recursos para a construção de um prédio que pudesse sediar as equipes e fosse mais acessível à população.

Ademais, coube aos profissionais e aos líderes comunitários a tarefa de apontarem a localização para a construção do novo prédio, considerando os dados sociodemográficos e os indicadores de saúde de cada localidade, além de monitorarem os prazos estabelecidos pela gestão municipal. Pinali21 ressalta que o número excessivo de pessoas cadastradas na unidade de saúde, além de acarretar demora no atendimento, gera insatisfação na comunidade e transtornos para profissionais e usuários.

Outra estratégia elaborada pelo grupo de intervenção para reorientação da demanda no serviço foi a otimização do acolhimento com classificação de risco à demanda espontânea, a ser realizada por um profissional de nível superior (médico ou enfermeiro), através de um esquema de rodízio entre os profissionais. Isso porque a manutenção de um profissional na retaguarda do atendimento à demanda espontânea permitiria que os demais se dedicassem aos atendimentos continuados aos grupos de maiores riscos e vulnerabilidades. O MS defende a importância do acolhimento aos usuários para a identificação das necessidades de intervenções de cuidado, humanização da assistência, continuidade da atenção e estabelecimento de vínculos ${ }^{22}$.

Destaca-se que, mais do que a construção da matriz de intervenção pelo grupo de pesquisa, o maior e mais importante produto deste estudo foi a mobilização e a aproximação de coletivos para discutirem uma problemática social e proporem estratégias democráticas de solução.

A participação social é um princípio doutrinário do SUS assegurado constitucionalmente, que incentiva usuários, gestores e 
profissionais a atuarem de maneira autônoma e representativa na gestão dos serviços de saúde, estimulando o exercício da cidadania e da corresponsabilização ${ }^{23}$.

A organização de coletivos é essencial para a efetivação desse princípio. Campos ${ }^{4}$ diz que coletivos organizados têm o papel de produzirem bens ou serviços com potencialidades para atenderem às necessidades sociais. $\mathrm{O}$ autor defende que instituições e a própria sociedade devem se organizar para assistir às pessoas. No entanto, reunir sujeitos heterogêneos, com interesses e poderes diferentes, em um mesmo propósito, emite uma polaridade paradoxal: produzir valores de uso que atendam às necessidades sociais e assegurar a organização dos sujeitos.

Para o enfrentamento desse paradoxo, Campos ${ }^{4}$ sugere a construção de uma nova correlação de forças que diminua as diferenças de poder entre os estamentos sociais, pactuando estruturas que consolidem situações mais equilibradas de poder. Para isso, uma alternativa seria a cogestão de coletivos.

Entende-se por cogestão (ou gestão participativa) o modo de administrar que inclui o pensar e o fazer coletivos. Tocci e Costa ${ }^{24}$ mencionam que, para a efetivação da cogestão, é preciso conhecer a realidade institucional e criar espaços de discussões que contextualizem impasses e desgastes, além de pensar e decidir coletivamente a organização do trabalho com gestores, usuários e trabalhadores. Neste processo, é fundamental o compartilhamento de saberes prévios, através de rodas de conversa, oficinas e reuniões, propondo soluções gerenciais e mudanças na organização do trabalho.

Para isso, o compartilhamento da gestão (cogestão) permite reconhecer, em qualquer circunstância, as divergências de interesses entre os agentes de produção e o público, também possibilitando que, apesar dos conflitos entre a lógica da produção de valores de uso (necessidades sociais e saúde, por exemplo) e os interesses particulares dos agentes e das instituições, seja possível considerá-los todos como objetivos legítimos e administráveis ${ }^{4}$.
A existência de conflitos em encontros que aproximam coletivos heterogêneos com interesses e poderes diferenciados é inevitável. Mediar tais conflitos por meio de técnicas de responsabilização comunitária é o objetivo dos processos de gestão participativa. E isto é possível quando se reconhece o campo da ESF como espaço de micropolíticas e de mudanças, e quando se busca minimizar o imperativo da culpabilização, que tende a prevalecer quando se juntam sujeitos de capital econômico e cultural diferentes para discutirem problemas sociais.

Por fim, considerou-se válida esta intervenção por estimular o compromisso democrático dos participantes e permitir o reconhecimento de que o benefício final da ação era de cunho social e não individual. E, também, por consentir que os sujeitos expressassem seus desejos e interesses particulares, ainda assim, assegurando a mediação de conflitos de interesses. Contemplaram-se, portanto, os critérios gerais do princípio da cogestão listada por Gastão Wagner Campos.

\section{Considerações finais}

O estudo evidenciou o despreparo dos coletivos para atuarem de maneira participativa na gestão do cuidado, ao tempo que revelou que as possibilidades de reestruturação dos serviços são mais factíveis quando pensadas de maneira democrática e corresponsável.

A transferência de responsabilidades nos processos de cogestão tende a ser um nó crítico desta proposta de trabalho. Por isto, é necessário estimular a ressignificação de práticas $\mathrm{e}$ atitudes, haja vista que as transformações nos processos de trabalho devem ser precedidas por transformações dos sujeitos.

Esta foi uma das dificuldades desta pesquisa: despertar a importância da participação dos sujeitos nas questões gerenciais dos serviços de saúde, desconstruindo o entendimento de que a gestão dos serviços públicos é de responsabilidade exclusiva da esfera governamental.

É tarefa árdua unir gestores, profissionais 
e usuários para desempenharem essa missão. Expõem-se as dificuldades de conciliar agendas de trabalho, interesses políticos e pessoais, além da não compreensão do papel social de defender os princípios do SUS, como alguns dos fatores que contribuem para esse desafio e foram vivenciados nesta pesquisa.

A limitação deste estudo está em seu escopo de compreensão cotidiana, que exige uma vivência singular e específica, restringindo-se a apenas uma unidade de saúde. Recomendamse, portanto, investigações adicionais para avaliar os resultados da implementação do plano elaborado nesta análise e suas evidências.

Espera-se que este trabalho possa auxiliar as demais equipes de ESF que também enfrentam dificuldades no dimensionamento da demanda, e que desperte o entendimento da importância da participação social no gerenciamento dos serviços, estimulando os coletivos a se organizarem de maneira continuada para solucionarem problemáticas do processo de trabalho em saúde.

\section{Referências}

1. Arantes L, Shimizu H. Contribuições e desafios da Estratégia de Saúde da Família na atenção primária à saúde no Brasil: Revisão de literatura. Ciênc. Saúde Colet. 2016; 21(5):1499-1509.

2. Franco TB, Merhy EE. A produção imaginária da demanda e o processo de trabalho em saúde. In: Pinheiro R, Matos RA. Construção social da demanda: direito à saúde, trabalho em equipe, participação e espaços públicos. Rio de Janeiro: Cepesc; Uerj; Abrasco; 2005. p. 181-93.

3. Barbosa A, Silva J, Araújo E, et al. Fórum Permanen-

\section{Agradecimentos}

Ao mestrado profissional em saúde da família, da Rede Nordeste de Formação em Saúde da Família (Renasf), nucleado na Universidade Regional do Cariri (Urca), por todo aprendizado e apoio para a realização do manuscrito que originou este artigo.

\section{Colaboradores}

Clemente MP (0000-0002-5613-8872)* contribuiu substancialmente para a concepção, o planejamento, a análise e a interpretação dos dados. Pinto AGA (0000-0002-4897-1178)* e Martins AKL (0000-0002-9382-1144)* contribuíram significativamente para a revisão crítica do conteúdo.

te de educação Popular em Saúde: Construindo Estratégias de diálogos e Participação Popular. Rev APS 2015; 18(4):554-559.

4. Campos GW. Um método para análise e cogestão de coletivos: a constituição do sujeito, a produção de valor de uso e a democracia em instituições: o método da roda. 5. ed. São Paulo: Hucitec; 2015.

5. Araújo A, Cruz P, Alencar I, Carneiro D. Educação Popular no Processo de Integração Ensino-Serviço e Comunidade: Reflexões com base em experiência na extensão. Rev APS 2015; 18(4):447-455.
${ }^{*}$ Orcid (Open Researcher and Contributor ID). 
6. Leal S. Organização da demanda espontânea e programada de acordo com a estratificação de risco [dissertação]. Porto Alegre: Universidade Federal de Ciências da Saúde; 2017.

7. Rocha H. Demanda espontânea da unidade básica de saúde de cachoeirinha em Belo Horizonte: plano de intervenção [dissertação]. Belo Horizonte: Universidade Federal de Minas Gerais; 2016.

8. Souza C, Botazzo C. Construção social da demanda em saúde. Physis: revista de saúde colet. 2013; 23(2):393-413.

9. Viegas A, Carmo R, Luz Z. Fatores que influenciam o acesso aos serviços de saúde na visão de profissionais e usuários de uma unidade básica de saúde de referência. Saúde. soc. 2015; (24):100-112.

10. Brasil. Ministério da Saúde, Secretaria de Atenção à Saúde, Departamento de Atenção Básica. Acolhimento a demanda espontânea. Caderno de atenção Básica 1(28). Brasília, DF: MS; 2013.

11. Brasil. Ministério da Saúde, Secretaria de Atenção à Saúde, Departamento de Atenção Básica. Acolhimento a demanda espontânea. Caderno de atenção Básica 2 (28). Brasília, DF: MS; 2013.

12. Araújo P, Assis M. Organização da demanda e ofertas de serviços na Estratégia Saúde da Família. Rev. Saúde.com. 2017; 13(4):994-1002.

13. Cassandre M, Querol A, Bulgacov Y. Metodologias intervencionistas: contribuição teórico-metodológica dos princípios vigotskyanos para pesquisa aprendizagem organizacional. 2012 [acesso em 2018 jul 14]. Disponível em: http://www.anpad.org.br/admin/ pdf/2012_eor1352.pdf.

14. Thiollent M. Metodologia da Pesquisa ação. 18. ed. São Paulo: Cortez; 2011.

15. Baldissera A. Pesquisa-ação: uma metodologia do "conhecer" e do "agir" coletivo. Soc. debates. 2001; 7(2):5-25.
16. Toi. Menino empurrando árvore. [ficheiro de vídeo]. 26 de novembro de 2007. [acesso em 2018 ago 21]. [02:07]. Disponível em: https://www.youtube.com/ watch? $\mathrm{v}=$ cinIaODneJo.

17. Toni J. O que é planejamento estratégico situacional? Espaço Acadêmico. 2004. [acesso em 2018 ago 21]. Disponível em: https://jacksondetoni.files.wordpress.com/2012/04/detoni_o-que-c3a9-o-pes-2004. pdf.

18. Santos LA, Torres AL, Ferreira MGF. Planejamento estratégico: instrumento transformador do processo de trabalho em saúde. Laborativa. 2019; 8(1):57-81.

19. Esmeraldo GROV, Oliveira LC, Esmeraldo Filho CE, et al. Tensão entre o modelo biomédico e a Estratégia Saúde da Família: visão dos trabalhadores de saúde. Rev. APS. 2017; 20(1):98-106.

20. Bitencourt AM. Ações educativas para orientação comunitária sobre o trabalho de uma equipe de saúde da família de Canápoles-MG [dissertação]. Uberaba: Universidade Federal de Minas Gerais; 2014.

21. Pinali TA. Sensibilização comunitária para enfrentamento da demanda espontânea em Estratégia Saúde da Família [dissertação]. Belo Horizonte: Universidade Federal de Minas Gerais; 2015.

22. Brasil. Ministério da Saúde, Secretaria de Atenção à Saúde, Departamento de Atenção Básica. Política Nacional de Atenção Básica. Brasília, DF: MS; 2017.

23. Fertonani H, Pires D, Biff D, et al. Modelo assistencial em saúde: conceitos e desafios para a atenção básica brasileira. Ciênc . Saúde Colet. 2015; 20(6):1869-1878.

24. Tocci A, Costa E. A gestão em saúde após a política nacional de humanização no Sistema Único de Saúde-SUS. Rev. Uningá. 2014; 40(1):197-206.

Recebido em 18/05/2020

Aprovado em 18/11/2020

Conflito de interesses: inexistente

Suporte financeiro: não houve 